\title{
Proceeding
}

Supplementary Issue: Winter Conferences of Sports Science. International Conference of Engineering, Innovation Technology and Applied Science.

\section{Using social network rates among Ardabil city women over 25 years old}

\author{
FIROUZ AMANI ${ }^{1}$, BAHMAN AGHAIE ${ }^{2}$, SOMAYEH ZEYNIZADEH ${ }^{3}$, SHERVIN TABRIZIAN ${ }^{4}$, ROGHAYEH \\ ASLANIAN $^{5}$, RAANA JAFARIZADEH 6 \\ ${ }^{1}$ Department of Community Medicine, Faculty of Medicine, Ardabil University of Medical Sciences, Ardabil, Iran \\ ${ }^{2}$ Nursing Department, Faculty of Nursing and Midwifery, Qom University of Medical Sciences, Qom, Iran \\ ${ }^{3}$ Department of Radiology, Faculty of Medicine, Ardabil University of Medical Sciences, Ardabil, Iran \\ ${ }^{4}$ Department of Obstetrics and Gynaecology, Faculty of Medicine, Ardabil University of Medical Sciences, Ardabil, Iran \\ ${ }^{5}$ Faculty of Medicine, Ardabil University of Medical Sciences, Ardabil, Iran \\ ${ }^{6}$ Department of Medicine, Ardabil Branch, Islamic Azad University, Ardabil, Iran
}

\begin{abstract}
Introduction: The role of women in the structure of society and family is very important. Unfortunately, due to the lack of proper planning to fill leisure time among people and especially women, overuse of social networks had a huge impact on their daily lives and in addition to the benefits, sometimes it has some problems. Method: This cross-sectional descriptive study has been done on 150 women over 25 years who selected randomly from Ardabil city in the 2018. Required information were collected using a research based questionnaire containing demographic and specialized questions about the rate of using social networks and their reasons. Collected data were analysed using descriptive and analytical statistical methods in SPSS version 21 . Results: The mean age of women was $34 \pm 9$ years. Of all women, $72 \%$ were married, $69 \%$ had graduated education, $27 \%$ were housewives, $44 \%$ were employees and $63 \%$ had a median income. Of all women, $94.7 \%$ were registered as members of social networks. Of them, $66 \%$ were registered on telegram. The most common reason for using Telegram, was chat and reading news. The maximum time spent with more than 5 hours for the social network was Telegram. Conclusion: Results showed that, most of the studied women have been used social networks and of them telegram and Instagram are more popular networks among Ardabil's women.
\end{abstract}

Keywords: Social Networks; Telegram; Instagram; Ardabil.

\section{Cite this article as:}

Amani, F., Aghaie, B., Zeynizadeh, S., Tabrizian, S., Aslanian, R., \& Jafarizadeh, R. (2020). Using social network rates among Ardabil city women over 25 years old. Journal of Human Sport and Exercise, 15(2proc), S429S436. doi:https://doi.org/10.14198/ihse.2020.15.Proc2.33

Corresponding author. Department of Medicine, Ardabil Branch, Islamic Azad University, Ardabil, Iran.

E-mail: ranajafari.137@gmail.com

Supplementary Issue: Winter Conferences of Sports Science. International Conference of Engineering, Innovation Technology and Applied Science.

JOURNAL OF HUMAN SPORT \& EXERCISE ISSN 1988-5202

(c) Faculty of Education. University of Alicante

doi:10.14198/jhse.2020.15.Proc2.33 


\section{INTRODUCTION}

The media plays an important role in the society and among them, the internet is a global media in which all knowledge and ideas are shared in it. Today, by development of ICT applications during life, we are seeing a new generation of Internet tools that creates more opportunities for mutual interaction, negotiation, dialogue and two-way communication. Cyberspace is a name that encompasses many of today's applications of new communication technologies and it was first invented by William Gibson in 1984 (Holmes, 2005). Social networks is a worldwide network that connects different computer networks of various sizes and even PCs using different hardware and software with conventions of communication. Tele communications technologies form the basis of cyberspace (Dehghan, 2005). In addition to advances in science and technology that have been assisted by humans in all fields, virtual networks have recently entered our lives and have filled most of our leisure time and daily programs. In recent years, social networks as the most popular achievement of the internet due to more reasons such as unlimited communication, anonymity, immense freedom, inertia and timelessness of users have been met with public interest and each of them according to their goals has expanded its activities (Disadvantages and Benefits of Cyberspace, 2016). Social networks by creating facilities such as creating personal profiles, the ability to send personal messages, adding people to your friends list and adding comments and comments make it easy, inexpensive and widely available for millions of people around the world. Although these networks not long lived but they bring together people of different ages, attitudes, beliefs and religions from far and near places and countries. These networks have been able to provide a large amount of social, political and economic information to their users in a very short period of time and attract audiences. E-mails, chat rooms, online games and web sites have expanded and maintained social relationships and millions of people visit these networks daily in worldwide (Yazdkhasti, 2003; Bagheri \& Bahadori-Jahromi, 2016).

Knowing users about social harms and social network threats could be very effective in preventing the consequences and reducing the harmful effects of this environment. Consequences such as removing family members from each other, creating mental addiction, jeopardizing personal security, emotional divorce, outof-family relationships, premature maturity, diminishing relationships and social interactions are the direct and indirect effects of social networks. Experts and humanities researchers believe that the advent of the internet into human life, along with its inevitable benefits has created a number of concerns and has greatly affected people's relationships (Disadvantages and Benefits of Cyberspace, 2016).

Females use social media less than men for business reasons, whereas women use social media to share more personal information than me, revealing more about their personal lives. Women are more vocal, expressive and willing to share. In other words, women are biologically wired for social networking. According this report, $58 \%$ of women used Instagram and $52 \%$ used Facebook and $47 \%$ used twitter (Men vs. Women: Who Is More Active on Social Media? 2015).

According to statistics, there are over 53 million (about 66\%) people in Iran connected to the internet via cell phone. The internet is now an inevitable part of each and every Iranian individual and many big start-ups are run within this space. What absorbs Iranians' attention the most amongst all these, is social networks.

Instagram is the most popular social media in Iran. There are over 24 million Iranian users of Instagram. Iran takes the 7th place in the list of active users of Instagram in the world. Instagram penetration rate is $29 \%$ in Iran (Social media in Iran, Instagram, Telegram and Twitter, 2018). 
In Iran, because of the expansion of the Internet and the availability of virtual social networks, the increasing number of these networks members and the impact of cyberspace on the real space of these networks has become important. The role of women in the structure of society and family is very important and influential. The rate to virtual networks uses among women may affect interactions between family members (Disadvantages and Benefits of Cyberspace, 2016).

Contrary to the study which most women use social media for their, the results of the study by Faraji et al showed that the use of social networks (Face book, Viber, line) is not effective on religious beliefs and religious emotions aspects (Faraji \& Taheri, 2015).

Since women form a large number of social network users in Iran, the purpose of this study was to investigate the uses rate of social networks among women over 25 years in Ardabil city.

\section{MATERIALS AND METHODS}

This study was a cross- sectional descriptive study which was done on 150 women over 25 years of age who selected randomly from Ardabil city in 2018. Required information collected by using a research based questionnaire containing demographic questions such as age, marital status, education level, employment status and income level and specialized questions such as membership in social networks (telegram, Facebook, Twitter, Instagram), use rate daily and reasons for using these social networks as well as location and use of internet. Collected data were analysed using descriptive and analytical statistical methods in SPSS version 21.

\section{RESULTS}

The average age of women was $34 \pm 9$ years. Of all women, $72 \%$ were single, $69 \%$ graduated, $27 \%$ were housewives, $44 \%$ employees and $63 \%$ had average income (Table 1). Of all women, $94.7 \%$ used social networks. Of them, 99 women (66\%) were registered in the telegram network, $19.3 \%$ in Instagram and the rest were in other networks (Figure 1). The most place for internet use among women was home with $77 \%$ (Figure 2). The highest rate of internet use was observed in < 1 hour per daily with $39.3 \%$ (Figure 3 ).

Table 1.Demographic data of women.

\begin{tabular}{|l|l|c|c|}
\hline Demographic data & $\mathbf{n}$ & $\%$ \\
\hline \multirow{2}{*}{ Marital status } & Married & 42 & 28 \\
\cline { 2 - 4 } & Single & 108 & 72 \\
\hline \multirow{3}{*}{ Education level } & Under diploma & 16 & 11 \\
\cline { 2 - 4 } & Diploma & 30 & 20 \\
\cline { 2 - 4 } & Graduated & 104 & 69 \\
\hline \multirow{5}{*}{ Job } & Non-employee & 23 & 15 \\
\cline { 2 - 4 } & Employee & 71 & 47 \\
\cline { 2 - 4 } & Free job & 16 & 11 \\
\cline { 2 - 4 } & Housekeeper & 40 & 27 \\
\hline \multirow{3}{*}{ Income } & Low & 36 & 24 \\
\cline { 2 - 4 } & Moderate & 95 & 63 \\
\cline { 2 - 4 } & High & 19 & 13 \\
\hline
\end{tabular}




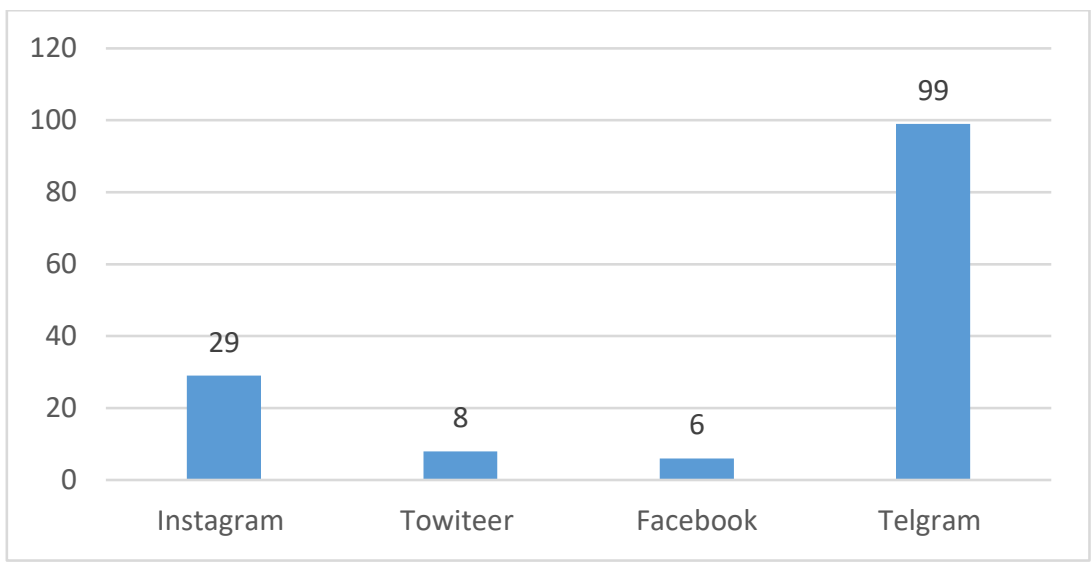

Figure 1. The frequency of using social networks among women.

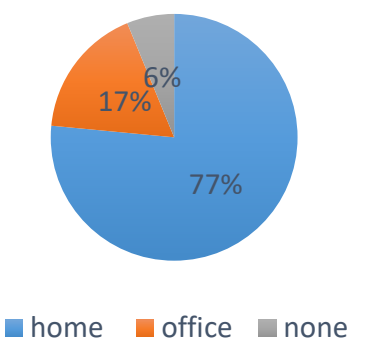

Figure 2. The frequency of internet using location among women.

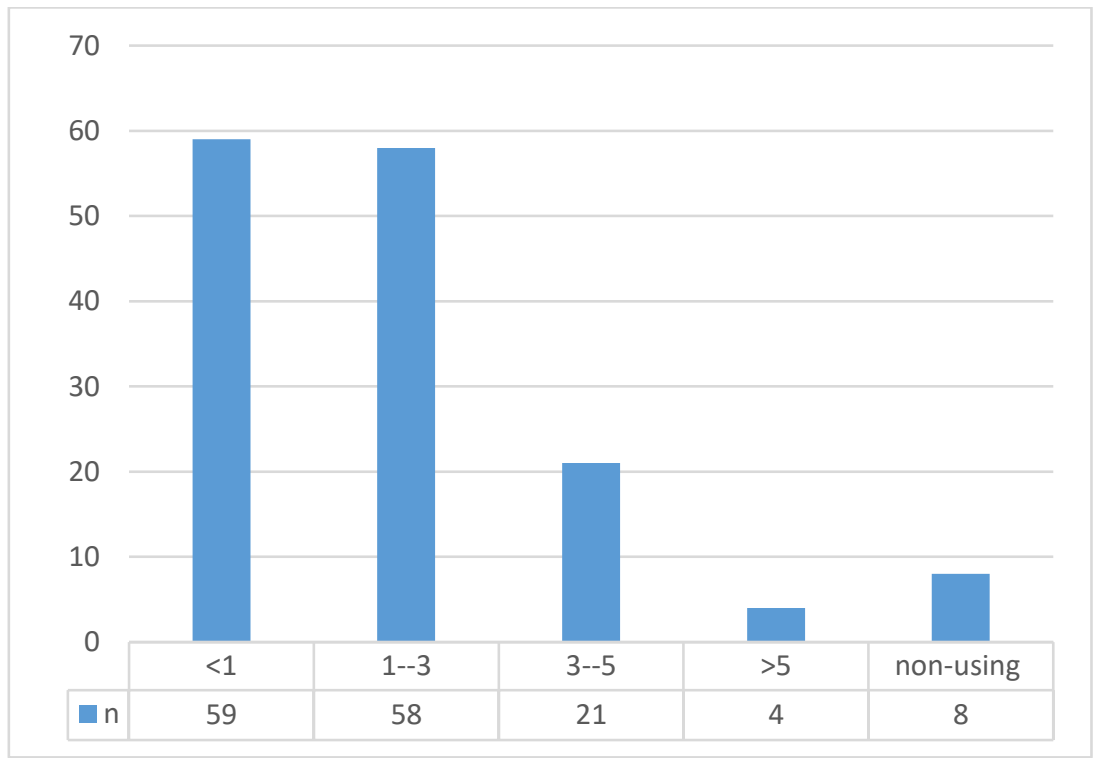

Figure 3. The uses rate of internet among women. 
The highest time spent on social networking was telegram with $41.4 \%$ was about $1-3$ hours and the least time spent less than one hour was on Instagram which was $48.3 \%$. The Telegram social network with $70.6 \%$ of the most internet users was between 1-3 hours (Table 2). The most frequent reasons for using Facebook, Instagram and Twitter were reading news with $50 \%, 58.6 \%$ and $87.5 \%$, respectively and most common reason for using telegram was chat and conversation with $50.5 \%$ and reading news with $40.4 \%$. The online shopping rate was $17.2 \%$ via Instagram (Table 3 ).

Table 2. The spent time for social networks among women.

\begin{tabular}{|l|c|c|c|c|c|c|c|c|}
\hline \multirow{2}{*}{ Hours } & \multicolumn{2}{|c|}{ Twitter } & \multicolumn{2}{c|}{ Telegram } & \multicolumn{2}{c|}{ Instagram } & \multicolumn{2}{c|}{ Facebook } \\
\cline { 2 - 9 } & $\mathrm{n}$ & $\%$ & $\mathrm{n}$ & $\%$ & $\mathrm{n}$ & $\%$ & $\mathrm{n}$ & $\%$ \\
\hline$<1$ & 4 & 50 & 38 & 38.4 & 14 & 48.3 & 3 & 50 \\
\hline $1-3$ & 3 & 37.5 & 41 & 41.4 & 11 & 37.9 & 3 & 50 \\
\hline $3-5$ & 1 & 12.5 & 16 & 16.2 & 4 & 13.8 & 0 & 0 \\
\hline$>5$ & 0 & 0 & 4 & 4 & 0 & 0 & 0 & 0 \\
\hline Total & 8 & 100 & 99 & 100 & 29 & 100 & 6 & 100 \\
\hline
\end{tabular}

Table 3. The reasons for use of social networks among women.

\begin{tabular}{|l|c|c|c|c|c|c|c|c|}
\hline \multirow{2}{*}{ Reasons } & \multicolumn{2}{|c|}{ Twitter } & \multicolumn{2}{c|}{ Telegram } & \multicolumn{2}{c|}{ Instagram } & \multicolumn{2}{c|}{ Facebook } \\
\cline { 2 - 10 } & $\mathrm{n}$ & $\%$ & $\mathrm{n}$ & $\%$ & $\mathrm{n}$ & $\%$ & $\mathrm{n}$ & $\%$ \\
\hline Reading news & 7 & 87.5 & 40 & 40.4 & 17 & 58.6 & 3 & 50 \\
\hline Game & 0 & 0 & 1 & 1 & 1 & 3.1 & 0 & 0 \\
\hline Chat & 1 & 12.5 & 50 & 50.5 & 5 & 17.2 & 3 & 50 \\
\hline Film download & 0 & 0 & 0 & 0 & 1 & 3.4 & 0 & 0 \\
\hline Shopping online & 0 & 0 & 8 & 8.1 & 5 & 17.2 & 0 & 0 \\
\hline Total & 8 & 100 & 99 & 100 & 29 & 100 & 6 & 100 \\
\hline
\end{tabular}

\section{DISCUSSION}

In the present study, $94.7 \%$ of women used social networks. In a study by Niromand et al, $54.7 \%$ of people agree with activity of women in social networks and Hosseini et al also in a study showed that, $66 \%$ of internet users were female (Niroomand \& Zohabi, 2015; Nami et al., 2017). In the present study, 34\% of women were used internet at home and for 1-3 hours but in another study conducted in Tehran, $49 \%$ of users used the internet about 4-8 hours per a day which was higher than our study results. In this study, the average age of women was 34 and $72 \%$ of them were single with college education, employed and middle income. In a similar study, there was no significant difference between the individual characteristics of women such as age, marital status and education level with their activity on social networks (Niroomand \& Zohabi, 2015).

There was statistically significant relationship between age and the type of social network because many of people at very young ages used specific social networks $(p=.02)$. No significant relationship was found in the study of Niromand (Niroomand \& Zohabi, 2015).

In this study, the most used social network was telegram and the most time spent on telegram. In a study by Bahadori et al, results showed a significant relationship between the duration of telegram use and social changes among youth (Bagheri \& Bahadori-Jahromi, 2016). 
In this study, women with a college degree were more likely to be on social media than other women and there was a significant statistical relationship between education and the type of used social network $(p=$ .001). In a study Nirodmand et al, there was no significant relationship between women's education and their activity on social networks which was inconsistent with the results of the present study but Gafari et al similar to the present study found a significant relationship between education and telegram use and showed that women with college education had a higher rate of use than other women.

Niroodmand et al in a study showed that, there was no significant relationship between marital status of women and their activity in social networks. Ghaffari et al showed that most of women who used telegram were housewives and married and the selected network was used to teach health and medical education and most of them felt satisfied with the network (Niroomand \& Zohabi, 2015; Ghaffari et al., 2017).

Married women were more likely to be on social media than single women and there was a significant relationship between marital status and the type of social network used by women but no significant relationship was found in the same study (Niroomand \& Zohabi, 2015).

In this study similar to the study by Niromand et al, there was no significant relationship between women's income and their activity on social networks (Niroomand \& Zohabi, 2015).

In this study, most of women used telegram to reading news (58.6\%) and but in a study, Ghaffari et al showed that most of women used telegram for visual and graphic work which was not in line with our study results (Ghaffari et al., 2017).

Capurro D et al similar to the present study showed that most of women used social networks for educational and learning purposes about women's health and medicine (Capurro et al., 2014).

In $2015,73 \%$ of online men and $80 \%$ of online women used social networking sites.

The rate of Instagram uses rate in our study was $19.3 \%$ which was the second social network after Telegram. The main reason for Instagram's popularity, probably is that people can watch a much better lifestyle in it. Radio and TV in Iran are owned and managed by the government, therefore, there is no private TV channel. So, people for share their videos and interested viewers need to use this social network because this is forbidden on Iranian national television. Therefore, the more national TV ignored people's interests, the more Instagram produced such content and attracted more and more users. The rate of Iranian users of Instagram was so remarkable that "Digital 2018" reported it was 135\%. Lao, most Instagram followers belong to celebrities like actors, singers, and soccer players (Social media in Iran, Instagram, Telegram and Twitter, 2018).

This means Instagram advertisement is greatly needed and different businesses find this social media a suitable means of communicating with their clients. Another social network is Telegram. The rate of Telegram uses rate in our study was $66 \%$ which was higher than other used social networks among studied women. Statistics showed that the number of telegram users in Iran exceeds 40 million nearly $50 \%$ which lower than our study results. Telegram is a messaging application. But after they added "Groups" and "Channels" feature, it turned to be one of the most popular social networks between Iranians. Before Telegram, the messaging application Viber was common between Iranians. But after Telegram came to play, all Viber users moved to Telegram, all of a sudden. The migration of users to Telegram was weird. The main reason could be censorship and banning common messaging and social networks. At the time when Telegram was 
launched, applications Viber, WhatsApp, WeChat and also Facebook and Facebook messenger were banned. This led users to Telegram.

After banning Telegram, over $80 \%$ of Telegram users kept using it by download VPN after it had been banned. The main reason why Telegram is so common in Iran is its user-friendly interface, its popularity and security. All age groups from teenagers to the elderly use it. Different-scale businesses, public relations, governmental and non-governmental organizations use it. This provides accessibility to whatever is needed by users. Telegram works as a messaging, blogging, online shopping, broadcasting, and advertising application. On the other hand, this ability to form groups and create channels has successfully replaced Facebook groups. So, Iranian users create their family, friends or colleagues' groups on this social media while there is no need for Facebook to communicate with only specific individuals. Iranian users believe that Telegram does not sell their private information to the government. All these reasons have encouraged Iranians to keep using this application in spite of being banned. There are over 30 channels on Farsi Telegram with more than 1 million members. Another social network is Twitter. The rate of Twitter uses rate in our study was $5.3 \%$ which was the third social network and near the country Twitter uses rate statistics. There is no accurate estimation of the number of active Iranian users of Twitter. But it can be estimated that about 5.5 million Iranians (nearly 7\%) use Twitter. Twitter can be named as the most important social media in Iran. Twitter is highly effective on Iran's political atmosphere and society. Currently this social network banned in Iran and the exact user rates is unknown.

Since early 2007, Facebook was used by Persian Users as social media. At first, it became common between people who had relatives living abroad but then gradually spread out in the whole society. Iranians most commonly used it between 2008 and 2012. Facebook was the first social media to affect Iranian society. Currently, there is no accurate statistics on the number of its users at hand. But it is obvious that the number of its users dramatically fell. In 2015, Iranian minister of culture and Islamic guidance declared that around 4.5 million Iranians (nearly 5.5\%) use Facebook which was similar to our study results because in this study about $4 \%$ of studied women used Facebook. Many studies have found that women are more likely to use either specific SNSs such as Facebook (Acquisti \& Gross, 2006; Joinson, 2008), or MySpace (Lenhart, 2009; Salaway \& Caruso, 2008; Caverlee \& Webb, 2008), or SNSs in general (Tufekci, 2008).

\section{CONCLUSIONS}

As most of the women in the present study used social networks such as telegram and given by the popularity of social networks among them, its increasing and popularity and also its positive and negative consequences, it could be exploited to plan and raise public awareness of people about its positive effects and achievements and minimized negative consequences. Therefore, it is suggested that similar studies be carried out in greater extent and with the presence of different strata of society. Given that most of the women in the study agreed with the activity of women on social networks, it is suggested that women be given awareness and information and culture- building on how to use social networks. Given that women's awareness about social networks was not enough, it is recommended that necessary training be provided to raise women's public awareness about social networks.

\section{REFERENCES}

Acquisti, A., \& Gross, R. (2006, June). Imagined communities: Awareness, information sharing, and privacy on the Facebook. In International workshop on privacy enhancing technologies (pp. 36-58). Springer, Berlin, Heidelberg. https://doi.org/10.1007/11957454_3 
Bagheri, H, \& Bahadori-Jahromi, S. (2016). Investigating the relationship between cyberspace use and social change among youth (Case study of Islamic Azad University of Bandar Abbas). Iranian Journal of Social Science Studies, 2, 189-197.[Full Text in Perisan]

Capurro, D., Cole, K., Echavarría, M. I., Joe, J., Neogi, T., \& Turner, A. M. (2014). The use of social networking sites for public health practice and research: a systematic review. Journal of medical Internet research, 16(3), e79. https://doi.org/10.2196/imir.2679

Caverlee, J., \& Webb, S. (2008). A large-scale study of MySpace: Observations and implications for online social networks (PDF). Paper Presented at the 2008 Meeting of the Association for the Advancement of Artificial Intelligence. Retrieved February 20, 2009.

Dehghan, A. R. (2005). Internet gambling. Journal of Iranian Association for Cultural Studies and Communication, 2, 45-73.[Full text in Persian].

Disadvantages and Benefits of Cyberspace. (2016). Available form: https://www.tasnimnews.com/fa/news/1395/07/05/1196921 [Text in Persian].

Faraji, F., \& Taheri, A. (2015). The effects of social networks (Face book, Viber, lines) on religious aspects of eighth grade girls in the city of Shiraz in academic year 2014-2015. Educational Research Journal, 3, 38-46.

Ghaffari, M., Rakhshanderou, S., Mehrabi, Y., \& Tizvir, A. (2017). Using social network of telegram for education on continued breastfeeding and complementary feeding of children among mothers: a successful experience from Iran. International Journal of Pediatrics, 5(7), 5275-5286.

Holmes, D. (2005). Communication theory: Media, technology and society. Sage.

Joinson, A. N. (2008, April). Looking at, looking up or keeping up with people? Motives and use of Facebook. In Proceedings of the SIGCHI conference on Human Factors in Computing Systems (pp. 1027-1036). https://doi.org/10.1145/1357054.1357213

Lenhart, A. (2009). Adults and social network websites. Pew Internet \& American Life Project.

Men vs. Women: Who Is More Active on Social Media? (2015). Available form: https://www.brandwatch.com/blog/men-vs-women-active-social-media/ January 28th 2015.

Nami, M. H., Hoseini, S. A., \& Karimi, A. (2017). Study and analysis the effects of cyberspace on geographical space and find out the relationship between the lack of feeling of security and distrust with using the internet.

Niroomand, L., \& Zohabi, S. (2015). Study Effective Factors on the Presence Level of Women in Networks Social of Virtual (Case Study: Women in Tehran).

Salaway, G., \& Caruso, J. B. (2008). The ECAR study of undergraduate students and information technology, 2008 (PDF). Retrieved February 20, 2009.

Social media in Iran, Instagram, Telegram and Twitter. (2018). Available from: . https://iranra.com/socialmedia-in-iran/ October 2018.

Tufekci, Z. (2008). Grooming, gossip, Facebook, and MySpace. Information, Communication \& Society, 11(4), 544-564. https://doi.org/10.1080/13691180801999050

Yazdkhasti, B. (2003). Public domain and social networking conversation. Journal of Communication Culture Studies. [Full text in Persian].

\section{(2) $\odot \Theta \Theta$}

This work is licensed under a Attribution-NonCommercial-NoDerivatives 4.0 International (CC BY-NC-ND 4.0). 